\title{
Respiratory disease: does ethnicity matter?
}

There is good and growing evidence that people from minority ethnic groups have worse health and die younger than people from majority groups [1]. These disparities cover a range of health problems and are rooted in a range of causes, including inherited factors, lifestyle, poverty and education. There is also good evidence that access to and delivery of care differ between ethnic groups, even within the same health care systems. Two reports recently published in the USA highlight these problems and call for remedial action $[2,3]$.

What of ethnic disparities for respiratory disease? Without doubt tuberculosis tops the list with the majority of the three million deaths per year occurring in the developing world [4]. More subtle but important inequalities exist elsewhere. Black people with early stage lung cancer in the USA are about half as likely as whites toundergo surgery and have lower 5-year survival rates [5]. For asthma, poorer outcomes for people from minority groups are a universal finding [6-9]. In New York, a black person with asthma is up to nine times more likely to die from asthma than people from other ethnic groups [6]. In New Zealand, the Maori population bore the brunt of the epidemic of asthma deaths in the 1980s; in South Africa and Singapore minority groups suffer poor outcomes $[7,8]$.

In the UK, hospital admission rates for asthma for all minority groups exceed those of whites (roughly double for South Asians) [9-11]. Access to routine and emergency UK primary care is rated poorly by people from black and Asian groups $[12,13]$. There is also evidence that what happens in consultations affects care. First, white people may benefit more from asthma education than people from South Asian groups, even when education is delivered in the patients' first language $[14,15]$. Second, differences may exist in the relationships patients have with their general practitioners: for those with more severe asthma, white people may have more constructive partnerships than South Asians, with action plans for emergency care [13]. Third, cultural differences between doctor and patient may be important. Explanatory models (health beliefs) of asthma and of airways obstruction held by Bangladeshi people in east London frequently include spiritual and supernatural, rather than structural or biomedical explanations [16]. Similar findings exist for understandings of mental distress (Ruddel K, personal communication). Dissonance in health beliefs of the patient and their doctor or nurse may hinder the effectiveness of education, particularly around rationales for different medications and the (western biomedical) notion of self-management [17].

What do these observations mean for delivery of care and further research? First, we need better and up-to-date information on respiratory care by ethnic group in the UK. This means promoting accurate recording of ethnicity in day to day care. Second, further work needs to address how best to deliver education for chronic disease management to minority groups. Lay-led education programmes are a promising option $[18,19]$ : it may be that the greater the cultural disparity between doctor and patient, the greater the potential benefit of education being delivered by a lay person from the patient's cultural or ethnic group. Third, the relationships between ethnicity, racism and health care need to continue to move up the list of research and political priorities $[20,21]$. Finally, we need trials testing promising interventions set in socio-economically deprived areas which include sufficient numbers of people from ethnic minority groups to draw useful conclusions about effectiveness [22].

Improving outcomes for minority groups is one of the most difficult challenges for health services. No interventions tested in randomised trials have reduced emergency asthma care for ethnic minority groups and studies in mixed white and minority populations have shown inconsistent results [23-25]. Improving outcomes in minority groups is vital: if health care interventions benefit white majority groups preferen- 
tially, the net effect is perversely to widen health inequalities.

\section{References}

[1] Altman D, Lillie-Blanton M. Racial/ethnic disparities in medical care. BMJ 2003;327:227E-8.

[2] Smedley BD, Stith AY, Nelson AR. Unequal treatment: confronting racial and ethnic disparities in health care. Washington, DC, National Academies Press; 2002.

[3] Physicians for Human Rights. The right to equal treatment: an action plan to end racial and ethnic disparities in clinical diagnosis and treatment in the United States. http://www.phrusa.org/research/domestic/race/race report/report.html. 2003.

[4] Grange JM, Zumla A. Paradox of the global emergency of tuberculosis. Lancet 1999;353:996.

[5] Bach PB, Cramer LD, Warren JL, Begg CB. Racial differences in the treatment of early-stage lung cancer. $N$ Engl J Med 1999;341:1198-205.

[6] Tanne JH. Asthma 'crisis' for black Americans. BMJ 2001;323:302.

[7] Ehrlich RI, Bourne DE. Asthma deaths among coloured and white South Africans: 1962 to 1988. Respir Med 1994;88:195-202.

[8] Ellison-Loschmann L, Cheng S, Pearce N. Time trends and seasonal patterns of asthma deaths and hospitalisations among Maori and non-Maori. N Z Med J 2002;115:6-9.

[9] Gilthorpe MS, Lay-Yee R, Wilson RC, Walters S, Griffiths RK, Bedi R. Variations in hospitalization rates for asthma among black and minority ethnic communities. Respir Med 1998;92:642-8.

[10] Ormerod LP. Adult Asian acute asthma admissions reassessed: Blackburn 1991-1992. Respir Med 1995;89:4157.

[11] Myers P, Ormerod LP. Increased asthma admission rates in Asian patients: Blackburn 1987. Respir Med 1992;86:297300.

[12] Campbell JL, Ramsay J, Green J. Age, gender, socioeconomic, and ethnic differences in patients' assessments of primary health care. Qual Health Care 2001;10:90-5.

[13] Griffiths C, Kaur G, Gantley M, Feder G, Hillier S, Goddard $J$, et al. Influences on hospital admission for asthma in South Asian and white adults: qualitative interview study. BMJ 2001;323:962.

[14] Griffiths C, Foster G, Barnes N, Eldridge S, Tate H, Begum $S$, Wiggens $M$, Dawson C, Livingstone A, Coats T, Chambers $M$, Feder, G. A specialist nurse intervention to reduce un- scheduled care for asthma in a deprived multiethnic area: the East London randomised controlled trial for high-risk asthma (ELECTRA). BMJ 2004;328:144-9.

[15] Moudgil H, Marshall T, Honeybourne D. Asthma education and quality of life in the community: a randomised controlled study to evaluate the impact on white European and Indian subcontinent ethnic groups from socioeconomically deprived areas in Birmingham, UK. Thorax 2000;55:17783.

[16] Foster G, Griffiths C. Ethnic differences in consultations for asthma: a qualitative and quantitative study. Society for Academic Primary Care; 2003, accepted for publication.

[17] Salmon P, Hall GM. Patient empowerment and control: a psychological discourse in the service of medicine. Soc Sci Med 2003;57:1969-80.

[18] Holman H, Lorig K. Patients as partners in managing chronic disease. BMJ 2000;320:526-7.

[19] Griffiths C, Ramsay J, Azad A, Motlib J, Eldridge S, Feder G. Expert Bangladeshi patients? A randomised trial of a lay-led self management programme for Bangladeshis with respiratory and cardiovascular disease. Eur Respir J 2003;22:S45, S409 [abstract].

[20] Bhopal R. Racism in medicine. BMJ 2001;322:1503-4.

[21] McKenzie K. Racism and health. BMJ 2003;326:65-6.

[22] Watt G. The inverse care law today. Lancet 2002;360:2524.

[23] Evans D, Mellins R, Lobach K, Ramos-Bonoan C, Pinkett-Heller $M$, Wiesemann $S$, et al. Improving care for minority children with asthma: professional education in public health clinics. Pediatrics 1997;99:157-64 [comment].

[24] George MR, O’Dowd LC, Martin I, Lindell KO, Whitney F, Jones $M$, et al. A comprehensive educational program improves clinical outcome measures in inner-city patients with asthma. Arch Intern Med 1999;159:1710-6.

[25] Castro M, Zimmermann NA, Crocker S, Bradley J, Leven C, Schechtman KB. Asthma intervention program prevents readmissions in high healthcare utilizers. Am J Respir Crit Care Med 2003;168:1095 $=9$.

Chris Griffiths

Department of General Practice \& Primary Care St. Bartholomews and Royal London School of Medicine London E1 4NS, UK

Tel.: +44-207-295-7954; fax: +44-207-982-6396

E-mail address: c.j.griffiths@mds.qmw.ac.uk (C. Griffiths)

Available online at www.sciencedirect.com science@Direct. 